\title{
EPISTEMOLOGIAS FEMINISTAS E CIÊNCIA DA INFORMAÇÃO: NOTAS INTRODUTÓRIAS
}

\author{
FEMINIST EPISTEMOLOGIES AND INFORMATION \\ SCIENCE: INTRODUCTORY NOTES
}

Carlos Cândido de Almeidaa

\begin{abstract}
RESUMO
Objetivo: Considerando as respostas aos problemas centrais que se impõem ao feminismo na ciência, o trabalho apresenta os tópicos gerais das discussões presentes nas epistemologias feministas tendo em vista subsidiar o artigo que tratará dos desdobramentos para a ciência da informação. Metodologia: O estudo utilizou uma abordagem bibliográfica, mas foi redigido na forma de ensaio. Na primeira parte se identificou a dificuldade de pensar o feminismo como uma corrente coesa. Para tanto, foi necessário revisar os conceitos básicos da discussão. Resultados: As perspectivas empirismo feminista, ponto de vista feminista e pós-modernismo feminista, são formas de responder aos problemas epistemológicos da ciência. Contudo, possuem limitações, embora sejam fundamentais para a reflexão da relação entre feminismo e ciência. Conclusões: Para as epistemologias feministas, assim como para o próprio movimento feminista, é necessário um combate ao relativismo, uma reinstauração do realismo e de um objetivismo mais potente que seja aperfeiçoado pela visão das mulheres, além da redução do paradigma do domínio da natureza e da sociedade e a inclusão de outros tipos de conhecimento como importantes para o início do processo heurístico, tal como a emoção. Com base nos argumentos relacionados, pode-se refletir sobre a ciência da informação e como as pesquisas no campo têm se posicionado frente às premissas epistemológicas feministas.
\end{abstract}

Descritores: Epistemologias Feministas. Ciência da Informação. Empirismo Feminista. Ponto de Vista Feminista. Objetivismo.

\footnotetext{
a Doutor em Ciência da Informação pela Universidade Estadual Paulista (UNESP). Docente do Departamento de Ciência da Informação da Universidade Estadual Paulista (UNESP). E-mail: carlos.c.almeida@unesp.br.
} 
Has feminism changed science?

[...] More important, feminism has

in many instances changed the content of human knowledge.

(Londa Schiebinger, 2001, p. 181)

\section{INTRODUÇÃO}

Tem sido comum referir-se ao feminismo, seja nas referências do senso comum ou nos meios de comunicação de massa, como um movimento social que prega a igualdade entre homens e mulheres. $O$ termo afronta-se com diversos temores por parte de vários setores da sociedade, especialmente no Brasil. Em primeiro lugar, grupos mais conservadores consideram feminismo uma ameaça a valores instituídos dentro de uma ou outra manifestação das crenças monoteístas e o associam, de maneira descabida, a problemas gerados pela própria estrutura social: a noção de família patriarcal, a competição no mercado de trabalho, a luta pelo poder político etc. Em segundo lugar, em um nível mais complexo, o feminismo defende-se de investidas mais sofisticadas que the acusam de um simples, mas poderoso, movimento político-ideológico que, como tantos outros, tem condenado as condições de exploração da mulher ao longo da história e clamando pela responsabilização. Terceiro, mas não menos importante, encontram-se também as falas de uma suposta equivalência entre feminismo e machismo, o que somente atrapalha o avanço do debate.

Seja em uma ou outra acepção, o feminismo não é compreendido. No primeiro caso, não há uma ideia clara do que significa, somente é usado como lema para afrontar políticas ou ideias que têm questionado o papel da religião e de costumes arcaicos com relação às liberdades individuais, para dizer o mínimo.

No segundo caso, assimilado em grande parte pela mídia e propagado por porta-vozes políticos, também não se oferece uma definição, e pior, o feminismo circunscreve-se semanticamente ao campo da luta ideológicopartidária. Nesse caso, seria apenas uma ideologia ou um projeto de poder como qualquer outro, diriam assim seus opositores. Sendo mais um projeto ideológico, 
segundo entendem seus detratores, seria válido e teria o mesmo peso para a sociedade como tantos outros, bastando ela escolher o mais interessante. Essa parece ser a pior acepção para significar feminismo, pois institui uma equivalência com propostas ideológicas, ademais de emitir sinais de que é tãosomente um movimento político, como outros, corporativos ou não, alinhados à esquerda ou à direita do espectro político.

No terceiro caso, a suposta oposição entre os conceitos feminismo e machismo traz prejuízos maiores, pois indica que as opressões e práticas de dominação presentes em um conceito estarão presentes no outro. Em outras palavras, a violência simbólica e objetiva do macho se converterá na violência perpetrada pela fêmea. Esse aberrante e assustador significado funciona de maneira calculada para manter a apreensão de pessoas pouco instruídas e reforçar as defesas das estruturas de poder dos machos frente às ações feministas.

Não obstante, deve-se pontuar que o feminismo é mais que um movimento política, embora este seja o seu "braço operacional" para ganhar espaço no debate público e na vida social. Considera-se importante aqui tratar do feminismo enquanto teoria, em concreto, uma teoria que também cobre a ciência. Deve-se tratar também de epistemologia feminista, isto é, uma resposta a problemas e às dificuldades de compreensão do mundo presentes nas ciências e como tal, deve ser examinado como uma perspectiva filosófica da instituição científica. Para Serret Bravo (2020, p. 85, tradução nossa), esta epistemologia surge para apontar "as falhas e as incongruências da epistemologia tradicional". É exatamente essa linha que se pretende seguir para compreender a epistemologia feminista e dela extrair reflexões para a ciência, de maneira geral, e para ciência da informação, em particular.

Argumenta-se que várias são os estudos têm citado o feminismo e a perspectiva de gênero na ciência da informação, mas não consideram o contributo epistemológico para a área como um todo. Em outras palavras, defende-se que não basta apenas levar a cabo pesquisas na ciência da informação ressaltando a perspectiva de gênero (embora fundamental para minorar a escassez de dados e de leituras de mundo), mas deve-se ir adiante e 
buscar propostas reformistas para a área. Ressaltar o ponto de vista feminino é imprescindível, mas é apenas o primeiro passo para uma renovação na concepção da ciência, neste caso, da própria ciência da informação.

Nesse sentido, uma ciência da informação que considera os parâmetros da epistemologia feminista seria concretamente uma ciência feminista da informação, ou seja, uma nova ciência da informação. Seria uma ciência que reconhece o patriarcado - que se apresentará mais adiante - como instituição principal de regulação da produção da informação e dos serviços de informação na sociedade e do qual outros desvios, preconceitos, discriminações se derivam. Considerar a informação dentro desse arco, é aceitar que a cognição desta está cercada de vieses simbólico-semióticos nos quais o principal decorre do gênero. Esses vieses se replicam nas narrativas da história da constituição do campo, nos processos de organização do conhecimento mas também nos dedicados ao acesso e à mediação da informação na sociedade. Nesta abordagem, compreender os papéis sociais representados pelos agentes em cada sociedade é imprescindível para entender como se opera a assimilação da informação.

Nessa nova ciência da informação, reconhece-se que as principais práticas dos profissionais que usam conhecimentos da área, desde as mais rotineiras e repetitivas até as mais abertas ao público, como seria o caso da mediação cultural, não romperam com uma epistemologia androcêntrica. Por mais inclusivos e plurais que sejam os discursos defendidos em congressos, por mais atentos à diversidade que autoras e autores afirmam em suas pesquisas, a ordem de fundo não sofreu uma mudança substancial.

Para começar a análise deve-se entender que há dois tipos genéricos de críticas feministas à ciência segundo Keller: críticas liberais e críticas radicais. As críticas liberais consistem em compreender que as acusações de androcentrismo da ciência são facilmente corrigíveis e implicam alterações na prática científica. Por exemplo, práticas injustas na empregabilidade, pois a maioria dos cientistas é homem (KELLER, 2005, p. 56-57). Notam-se na literatura da ciência da informação, como se verá em outro estudo, acusações nesse sentido visando uma maior integração de mulheres em cargos de comando e representação política na área. 
Por outro lado, as críticas radicais exigem mudanças mais profundas, revisão dos pressupostos e dos métodos para detectar os vieses sexistas. Por exemplo, a predominância de homens influencia a escolha de problemas da ciência, especialmente na área de saúde (dar ou não ênfase aos estudos sobre contracepção); as investigações com animais têm privilegiado ratos machos (KELLER, 2005, p. 57). Essas críticas radicais não consideram suficiente a participação de mais mulheres no mercado de trabalho, como se verá adiante. Contudo, reconhecem que "[...] a predominância de homens nestas áreas, tem influenciado de modo substantivo as teorias científicas, incidem sobretudo sobre as ciências 'moles' e mesmo sobre as mais 'moles' de todas." (KELLER, 2005, p. 58). Essas críticas poderiam ser renomeadas de críticas à ciência mais superficiais ou horizontais (liberais) e profundas ou verticalizadas (radicais).

Entende-se que as críticas radicias devem ser o objeto principal de reflexão da ciência da informação caso se pretenda uma renovação nas formas de se produzir conhecimento na área. Pensar a ciência da informação no marco de uma discussão epistemológica feminista deve identificar as críticas liberais e mais simplistas, e separá-las das críticas radicais. No caso, a ciência da informação, assim como outras ciências sociais, poderia reconhecer nas críticas radicais formas de se desprender de um modelo de ciência que se intenta constantemente imitar. Prova disso está na sempre e constante formalização dos estudos que tratam de problemas sociais na ciência da informação. Além disso, a própria crítica radical oferecida pela epistemologia feminista pode evitar que se caia em ciladas teóricas ou que se admita narrativas pouco afeitas ao que a ciência tem proporcionado a todas e a todos, apesar de seus defeitos e limitações.

Este primeiro artigo, escrito na forma de ensaio, pretende retomar elementos da epistemologia feminista para, em um segundo momento, tratar dos desdobramentos para a própria epistemologia da ciência da informação. Para tanto, é necessário apresentar conceitos básicos da discussão e lançar as inferências decorrentes para melhor compreender as pesquisas sobre $o$ assunto na ciência da informação. 


\section{DOS FEMINISMOS}

Será o feminismo apenas um movimento social e político? Acredita-se que a pergunta básica não é exatamente essa. O feminismo não pode ser entendido no singular. Deve-se destacar que há muitas expressões do feminismo, ou seja, feminismos. É certo que, segundo Sau (2000, p. 121), o feminismo é considerado um movimento social e político iniciado no final do século XVIII que significou a conscientização do grupo de mulheres com respeito à opressão e à exploração a que foram submetidas.

Há ainda uma simplificação corrente de que o movimento feminista é tão somente uma expressão da pós-modernidade, assim como os demais movimentos reivindicatórios, como no comentário de Martínez: "Igualmente, o Movimento Feminista, em geral, pode ser visto como uma extensão da província de Orientação Pós-moderna" (MARTíNEZ, 2003, p. 51, tradução nossa). Como se perceberá, a discussão feminista epistemológica exige um pouco mais de profundidade, até mesmo para reconhecer as contradições entre o pós-moderno e o feminismo.

Evans (Evans apud SAU, 2000, p. 122) indica que o termo surgiu na França (feminisme) e foi adotado na Inglaterra (feminism) em 1890, o que substituiu o termo womanism (mulherismo) e apareceu na Espanha em 1899. Sem entrar nos detalhes das iniciativas políticas feministas de grande importância ao longo da história, é oportuno mencionar as diversas manifestações do feminismo, ou os feminismos. Cada perspectiva está ligada a um ponto de vista ou mesmo a uma luta específica e concreta. Essa mesma multiplicidade pode ser encontrada no estudo epistemológico da ciência. $O$ objetivo desta seção é mostrar um pouco dessa variedade e como pode ajudar a pensar os problemas da ciência.

Seguindo a análise de Sau (2000), ter-se-iam os seguintes tipos: feminismo burguês que objetiva obter os mesmos direitos e oportunidades, mas sem questionar o modelo socioeconômico, seria um tipo reformista e não revolucionário. O feminismo sufragista é um tipo burguês voltado para a conquista do voto, já o feminismo católico é representado pelas lutas pelo direito 
à educação, igualdade de salários e denúncia da prostituição, pelo direito ao sacerdócio e pela valorização das mulheres no trabalho da igreja. Ainda segundo a autora, o feminismo socialista possui em geral uma dupla militância, contra a sociedade capitalista dentro do partido e por causas específica das mulheres trabalhadoras, assim tendem a ver mulheres burguesas como inimigas da classe. O feminismo radical, por sua vez, defende uma organização sem homens e lutam contra as instituições patriarcais, pois consideram que o socialismo não é suficiente para que as mulheres sejam realmente livres, como ressalta a autora: o socialismo não supõe o feminismo, mas o feminismo pode conter 0 socialismo (SAU, 2000).

Sau (2000) comenta que o feminismo homossexual é a expressão da luta das mulheres pelo direito à vida sexual sem interferências externas, do estado ou de qualquer outra autoridade; este assume posturas do feminismo radical. Por outro lado, o feminismo da diferença defende as qualidades femininas que supõem ser própria da mulher, como sensibilidade, intuição e menor agressividade; pois temem que a igualdade política e laboral possa aproximá-las aos homens em termos de competitividade, insensibilidade e senso de agressão. Já o feminismo de partido é uma expressão do feminismo radical que surgiu no final dos anos 1970 e início dos anos 1980 na Espanha, Estados Unidos e Alemanha. Assim como este último, o feminismo oficial não é necessariamente um tipo particular, pois está submetido a uma estrutura burocrática de uma das forças políticas dominantes para canalizar as demandas por direitos e necessidades das mulheres, como é o caso da luta das mulheres no contexto das Nações Unidas.

Ao feminismo oficial, também chamado por Varela Menendez (2019, p. 123) de feminismo institucional, vem a somar-se o ecofeminismo, o qual integra ao feminismo a espiritualidade e a preocupação ecológica das mulheres ambientalistas das regiões pobres do globo, como América Latina, Ásia e África. Esse movimento critica os movimentos de feministas de países ricos, de corpos brancos, classe média e cristão (PÉREZ PRIETO, 2017). As ecofeministas lutam contra os impactos do capitalismo global e reconhecendo os conhecimentos tradicionais. Além disso, Varela Menendez (2019, p. 128) inclui o ciberfeminismo 
pois promove o uso das novas tecnologias para construir uma identidade independente no ciberespaço cujo primeiro congresso internacional ocorreu em 1997 na Alemanha. Pode-se acrescentar ainda o feminismo negro, como a expressão do feminismo que cobre os problemas vividos pelas mulheres negras que estão na base da pirâmide social em várias sociedades, discutindo a interseccionalidade entre os sistemas de opressão de gênero, classe e raça.

Há, obviamente, uma disputa entre as narrativas dessas frentes de atuação do feminismo e isso não deixou de ser notada pelas teóricas do feminismo: "Uma tensão que vejo menos discutida é a que ocorre entre as mulheres com elevado nível educacional do feminismo académico (de qualquer disciplina) e, principalmente, as mulheres das classes trabalhadoras." (ROSE, 2005, p. 116). A intenção não é adentrar nas especificidades dos feminismos, mas sustentar a premissa de que não é possível tocar nesse assunto sem antes reconhecer a sua pluralidade.

Deve-se evitar os reducionismos e tratar sempre dos feminismos de modo a compreender as diversas linhas explicativas, bem como as expressões da coletividade de mulheres. Essa questão é realmente difícil, e também foi lembrada por Haraway (2020, p. 38),

Estas taxonomias tendem a refazer a história feminista para que esta represente uma luta ideológica entre tipos coerentes que persistem através do tempo, especialmente essas típicas unidades chamadas feminismo radical, liberal e socialista.

Esse embate desdobra-se diferentemente conforme o estágio de desenvolvimento da discussão do feminismo nos diferentes países. Por exemplo, atualmente no Brasil, o feminismo institucional tem se apresentado no âmbito legislativo; o problema é que muitas representantes parlamentares do movimento das mulheres na Câmara dos Deputados e no Senado, vinculam-se a pressupostos do feminismo católico (em nosso caso, mais neopentecostal que católico) ou do feminismo burguês. Poucas são as parlamentares em âmbito federal que se identificam claramente com os feminismos radical, socialista, ecofeminista, homossexual e negro. Desse modo, a revolução social pretendida segue a passos lentos, quando não sofre verdadeiros retrocessos como nesta legislatura. Borges (2019) registra que passamos de 13 para 12 senadoras na 
atual legislatura. Contudo, a análise mais detida revela que apenas duas estão vinculadas a partidos associados ao espectro centro-esquerda.

\section{AS EPISTEMOLOGIAS FEMINISTAS NO PLURAL}

No caso específico da teoria do conhecimento científico funcionaria da mesma forma. As epistemologias feministas, tendo por base os diversos feminismos existentes, acusam - e procuram provar - que a instituição ciência reproduz desigualdades encontradas em outras esferas da vida. A ciência não consegue se desprender do fato que é uma instituição social e cultural que possui regras de convivência, normas de desempenho, narrativas integradoras e uma cosmovisão fundada em uma percepção da natureza e dos seres humanos. Questionar a ciência, assim como as demais instituições da sociedade, não seria possível sem o surgimento das diversas lutas do feminismo.

Para compreender a teoria feminista do conhecimento é importante considerar algumas ideias fundamentais, segundo Serret Bravo (2000, p. 85-87). A primeira é que a teoria tradicional, fundada na epistemologia moderna, não permite conhecer a realidade humana porque oculta o ponto de vista da metade da população. A segunda consideração é que a linguagem, os conceitos e as perspectivas tornam invisíveis expressiva parte dos seres humanos. Terceira: 0 modelo de ser humano centra-se nos homens, brancos e heterossexuais. Por último, a perspectiva feminista pretende abarcar de maneira mais correta a realidade humana.

É notório que as mulheres não têm espaço na academia e nos postos de trabalho mais altos ocupados comumente por pesquisadores homens. Essa defasagem não tem a ver com as predileções femininas sobre uma dada área em detrimento de outra. O problema real começa ainda quando as meninas confrontam-se com todo o tipo de dificuldades e barreiras para receber uma educação de qualidade.

Para resgatar a centralidade do assunto e fazer avançar a teoria dos comportamentos sociais, o movimento feminista, seja acadêmico ou político, tem desenvolvido conceitos-chave para compreender a realidade social. Segundo explicado por Varela Menéndez (2019, p. 175) os conceitos seriam: patriarcado, 
androcentrismo, gênero e sexismo.

Explicado de forma breve, para Varela Menéndez (2019), a ideia geral é que se está em um sistema e uma estrutura de governo cuja autoridade máxima são dos varões onde subjaz as práticas econômicas, políticas, religiosas e culturais. Ainda que o patriarcado seja complexo e tenha níveis mais centralizados e explícitos, ou outros mais fragmentados e implícitos, o núcleo da representação da realidade ainda está localizado no varão.

Continua a autora, o padrão de ser humano que constrói as expressões da realidade cultural é o que se entende como androcentrismo. É importante que as ciências sociais saiam do androcentrismo onde estão presas. Sau (2000, p. 45 , tradução nossa) resume a ideia dizendo que se trata de tomar "O homem como medida de todas as coisas." Para Sau (2000, p. 45) é a insistência de um enfoque centrado na visão masculina e projetado como válido para os demais indivíduos, o qual tem deformado ciências importantes como história, etnologia, antropologia, medicina, psicologia etc.

Por gênero se entende "a construção social e cultural da feminilidade e masculinidade" (RODRíGUEZ MAGDA, 2020, p. 119, tradução nossa). Em outras palavras, trata-se de um fato cultural e não de uma característica biológica. De acordo com Schiebinger (2001, p. 16), o termo foi introduzido no debate nos anos 1970 como um esforço de combater o determinismo biológico e distinguir as formas específicas de manifestação da masculinidade e da feminilidade das formas biológicas do sexo, construídas a partir de cromossomos, fisiologia e anatomia.

Para manter os sistemas de reprodução dos papéis sociais e as vantagens adquiridas na estrutura de poder constituída, o patriarcado deve recorrer a meios, estratégias e métodos classificados como sexismo. Seria o conjunto de formas de implementar a subordinação das mulheres, apartá-las das posições de comando, redistribuir os papéis sociais e perpetuar a desigualdade. Em uma analogia, para Varela Menéndez (2019, p. 180, tradução nossa), "machismo é uma cantada enquanto sexismo é a divisão da educação por sexos". É pelo sexismo que se estabelecem os deveres e o raio de ação de homens e mulheres na sociedade como forma de evitar a igualdade em 
obrigações e direitos. Pode-se aqui desenvolver uma análise das diversas formas de sexismo, da estrutura patriarcal, dos vieses do androcentrismo e do conceito de gênero, contudo, para esta discussão, esses elementos introdutórios são suficientes para aproximar-se das implicações no contexto científico.

As epistemologias feministas estão sustentadas pelos conceitos anteriores, os quais estão entrelaçados. Talvez o principal deles para discutir a ciência seja o androcentrismo, pois atua na compreensão última que afeta todas as instâncias da ciência: cosmovisão em relação à natureza e à sociedade, teorias, leis, conceitos, métodos e organização institucional. A importância do androcentrismo não é uma dispensa dos conceitos de sociedade patriarcal, sexismo e gênero. Estes, por sua vez, são utilizados para explicar desdobramento do androcentrismo na ciência.

Por exemplo, o androcentrismo leva a uma organização da ciência em que a participação das mulheres é residual, especialmente nas ciências naturais (especialmente física e química). Contudo, para levar a cabo esta institucionalização que legitima uma visão androcêntrica da natureza, há que se recorrer ao sexismo no acesso aos postos de trabalho, especialmente no comando das grandes equipes de pesquisadores em nível internacional.

A própria desconstrução de preconceitos sobre a participação das mulheres na ciência recorre ao termo gênero para sustentar que os esteriótipos foram socialmente construídos e que o desempenho em matemática pode ser alcançado com igual nível de êxito por meninas e meninos. Por esta razão, embora considera-se neste trabalho 0 androcentrismo fundamental para a discussão epistemológica, é impossível a reflexão sobre o assunto sem o auxílio dos conceitos de gênero, patriarcado e sexismo.

Há questões críticas, porém defensáveis, no debate epistemológico feminista que merecem atenção. Alguns críticos sustentam que as questões feministas não oferecem comprovações a falta de neutralidade de alguns enunciados científicos, considerados crenças confirmadas e insuspeitas. Contudo, prefere-se adotar a percepção de Schiebinger (2001), para quem, os estudos de gênero podem oferecer novas perspectivas, novos projetos de pesquisa e novas prioridades. 
Mesmo que a questão da objetividade na ciência não possa ser questionada pela epistemologia feminista, o fato de pôr atenção a fenômenos ainda não investigados já significaria um avanço. Esse é o caso, por exemplo, de fenômenos de grande importância social como a saúde das mulheres e de crianças, investigada na medicina e na farmacologia. Também se acrescentam as preocupações de campos aplicados, como arquitetura e engenharia, promovendo melhores espaços de convivência social, cidades e tecnologias que reconhecem as necessidades específicas de mulheres e crianças. A própria valorização de outras necessidades e o estabelecimento de novas prioridades de pesquisa, que recorram ao conhecimento e ao método científico, já seriam vantagens de se integrar o pensamento feminista à ciência.

Entende-se que a epistemologia da ciência alinhada ao feminismo também não seria compreendida adequadamente no singular. As propostas feministas à ciência, às vezes coincidentes, outras vezes destoantes, devem ser compreendidas enquanto um conjunto de preocupações epistemológicas que procura questionar a ciência estabelecida e superar os problemas da epistemologia tradicional. Concebem-se como tradicionais os ideais de objetividade, universalidade e neutralidade da ciência ou da ciência moderna na versão esquemática de Santos (2000).

\subsection{Propostas a Questões Epistemológicas}

Há questões epistemológicas que o feminismo tem enfrentado. Pode-se entender que fazem parte de um debate mais profundo referente aos tipos de críticas mencionadas por Keller (2005) e centram atenção nas bases da ciência. Harding (2016, p. 11, tradução nossa) argumenta que "A postura feminista radical sustenta que as epistemologias, metafísicas, éticas e políticas das formas dominantes da ciência são androcêntricas". Com isso, a percepção do objeto do conhecimento pelo sujeito são questionados em sua neutralidade. Até mesmo a noção de sujeito deve ser revisada, pois normalmente refere-se a um homem com capacidades cognitivas para conhecer um objeto exterior (a sociedade, a natureza e o universo). Além disso, há perguntas que a preocupação feminista da ciência deve ocupar-se para superar a visão supostamente ideologizada de 
seu discurso.

Seriam duas perguntas aludidas por Harding (2016, p. 23) de máxima importância para a discussão. A primeira, como esse movimento tão politizado pode aumentar a objetividade da pesquisa científica? E a segunda: sobre qual fundamento poderia se justificar as afirmações feministas?

Essas perguntas resumem bem um grande conjunto de críticas endereçadas ao feminismo quando este se arvora a questionar a ciência, seus métodos, estruturas e hierarquias. Destaca-se que o objetivo está marcadamente interessado em renovar o pacto com a ciência, mas sob um novo paradigma. Não se trata de renegar a ciência e os avanços conquistados, devese ter clareza disso.

Para solucionar as perguntas candentes, Harding (2016) relaciona três soluções possíveis dentro do espectro das epistemologias feministas: o empirismo feminista, o ponto de vista feminista e o pós-modernismo feminista. Essas tendências marcam posições que permitem entender melhor a natureza e os objetivos de estudos levados a cabo na ciência da informação.

A primeira solução epistemológica (empirismo feminista) sustenta que o sexismo e o androcentrismo são vieses sociais corrigíveis utilizando as normas metodológicas da própria ciência. $O$ fato de ter mais mulheres na ciência favorecerá a identificação de vieses androcêntricos. Assim, será fácil resolver o problema da objetividade, mas as normas da ciência seguirão intactas. O método científico quando aplicado por mais mulheres corrigirá automaticamente os vieses. Segundo Harding (2016, p. 24, tradução nossa), "Presume-se que o método é capaz de eliminar os vieses devido ao fato dos pesquisadores concretos sejam brancos ou negros, chineses ou franceses, homens ou mulheres."

Não obstante, para esse empirismo, as mulheres podem obter resultados não enviesados mais que os homens, sejam feministas ou não. O problema, sustenta Harding (2016), não é a ciência que se corrige a si mesma ao longo dos anos com o uso correto do método científico e assim garante a objetividade, mas os movimentos de libertação social são os que têm aumentado a objetividade científica. A ideia do empirismo feminista como solução à objetividade se 
considera muito ingênua e propõe que a mudança depende da estrutura interna da ciência. Em outras palavras, a solução estaria na própria ciência e na aplicação rigorosa de seu método contando com mais participantes mulheres.

O empirismo feminista estaria dentro da crítica liberal apresentada por Keller (2005). Nessa ligeira compreensão do problema, a ocupação de cargos seria suficiente para a remodelação da instituição científica. Contudo, não se questionam os paradigmas da ciência que, em essência, estariam corretos.

Uma estratégia governamental, nesse sentido, seria a adoção do modelo funil, isto é, pressupõe que as mulheres e as minorias devem assimilar a prática corrente da ciência. Não obstante, essa estratégia não discute como a estrutura das instituições ou as práticas correntes da ciência precisam alterar-se antes das mulheres se juntarem aos cientistas (SCHIEBINGER, 1999, p. 64). Se mais mulheres entrarem no funil ou na tubulação do fluxo educacional, mais mulheres conseguiriam converter-se ao final em especialistas credenciadas ao trabalho na ciência (SCHIEBINGER, 1999, p. 54). Essa proposta, mencionada por Schiebinger, é uma manifestação ingênua do empirismo feminista, uma crença e ao mesmo tempo um reforço a imutabilidade das práticas tradicionais nas ciências. Esse processo de renovação não se daria de forma automática.

A proposta empirista, ou seja, inserir mais mulheres na ciência, não consegue solucionar por completo, por exemplo, um problema mais profundo que consiste na dificuldade de mulheres alcançarem os postos de trabalho mais altos dentro da hierarquia acadêmica. Ali encontram-se outros problemas de ordem institucional que não são resolvidos pelo simples acesso às mulheres aos espaços da prática científica. O fenômeno teto de vidro está presente na ciência, assim como em outras instituições sociais, mostrando que a simples presença no espaço não garante a correção ou mudança na estrutura. É justamente nos postos mais elevados da ciência em que se definem as políticas científicas e o que será considerado científico ou não.

A segunda possível resposta ao problema epistemológico é o ponto de vista ou perspectiva feminista da ciência. Este considera que o conhecimento do homem é parcial e perverso, pois subjuga as mulheres, assim como faz em outras esferas da vida social. Essa linha tem uma vinculação estreita com o 
marxismo, mas acrescenta que o ponto de vista das mulheres abre outras possibilidades de conhecimento antes não possíveis por incompleta compreensão masculina que, ademais, explorava as mulheres.

Contudo, assim como o empirismo feminista, a resposta do ponto de vista feminista também pode sofrer críticas, como assinalado por Harding.

\begin{abstract}
Ainda que esta tentativa de solução do paradoxo epistemológico evita os problemas que propõe o empirismo feminista, também gera suas próprias tensões. Em primeiro lugar, aqueles que estão apegados ao empirismo se mostram receosos a aceitar a ideia de que a identidade social do observador pode ser uma variável importante com respeito a objetividade potencial dos resultados da pesquisa. De um ponto de vista estratégico, esta explicação da maior adequação das proposições feministas é menos convincente, salvo para aqueles que já estão convencidos; é muito improvável que os cientistas naturais ou os partidários da ciência natural de ambos os gêneros aceitem esta postura. (HARDING, 2016, p. 25, tradução nossa)
\end{abstract}

A autora acrescenta ainda outro questionamento sobre o ponto de vista feminista. Dada a pluralidade de visões e circunstâncias, como ter "um" ponto de vista ou perspectiva feminista sem considerar as posições socialmente construídas, tanto para mulheres feministas ou não feministas. Nesse caso, como conciliar em um único ponto de vista as relações distintas entre classe social, raça e cultura. Em outras palavras, poderia haver vários pontos de vista feministas relacionados à classe, raça, profissões e a outros determinantes sociológicos e culturais.

Assim, como seria possível reduzir a complexidade de pontos de vista em uma perspectiva única? Essa mesma complexidade também pode ser observada no movimento social feminista. $O$ fato de mulheres participarem ativamente da ciência não significa obrigatoriamente um compromisso com um ponto de vista feminista em particular. Em muitos casos, a ideologia científica oblitera particularidades e individualidades, ou pelo menos assim se supõe. A presença feminina não altera automaticamente a ciência. É a reformulação do modelo de ciência que altera as práticas.

A terceira resposta epistemológica é a feminista pós-moderna. Essa linha contesta os pressupostos anteriores do empirismo e do ponto de vista feminista. Para Harding (2016, p. 26), a corrente reúne pensadores como Nietzsche, 
Derrida, Foucault, Lacan, Rorty, Cavell, Feyerabend, Gadamer, Wittgenstein, Unger, além de disciplinas e teorias como semiótica, descontrução, psicanálise, estruturalismo, arqueologia, genealogia e nihilismo.

De acordo com Flax (apud Harding, 2016, p. 26, tradução nossa) as feministas dessa linha "compartem um profundo ceticismo com respeito aos enunciados universais (ou universalizadores) sobre a existência, a natureza, as forças da razão, o progresso, a ciência, a linguagem e o 'sujeito/eu'." Com efeito, a recusa a tudo que está estabelecido pode parecer mais uma estratégia política que uma resposta de carácter teórico, pois oferece interpretações que esperam que sejam universais ou pelo menos mais explicativas ou compreensivas que as anteriores. Harding (2016) afirma que são as tensões e contradições da própria epistemologia feminista pós-moderna, assim como presente em outros discursos epistemológicos feministas.

Essas tensões entre feminismo e pós-modernidade são observadas em um âmbito mais geral. Benhabib (2020) comenta as dificuldades para o feminismo incorporar algumas teses da pós-modernidade. Sustentada em Jane Flax, a autora Benhabib (2020) comenta que a posição pós-moderna se apoia nas teses da morte do homem (das concepções do ser e da natureza humana), da história (da história do homem e da ideia de progresso) e da metafísica (das concepções do real e da verdade, objetos a serem dominados pelos sistemas filosóficos ocidentais). A questão é que o pós-moderno pode sugerir ao movimento feminista a dispensa de um pensamento emancipatório fundado na reflexão racional e da busca de uma utopia feminista.

Segundo Braidotti (apud BENHABIB, 2020, p. 328), como seria possível conceber a morte de um sujeito cognoscente como admissível pelo feminismo sendo que este nunca se realizou plenamente. Em outras palavras, primeiro as mulheres precisam alcançar o status de sujeito, disputar o uso da palavra e dominar outros signos ditos do sujeito para, então, subverter o sistema. Como sugere Braidotti, essa tentativa contemporânea de desconsiderar o sujeito tem o efeito imediato de ocultar os intentos da mulher para ter voz teórica própria. Benhabib (2020, p. 341-342, tradução nossa) conclui afirmando que

A renúncia à utopia na teoria feminista na última década tem consistido de tachar de essencialista qualquer proposta de 
formular uma ética feminista, uma política feminista, um conceito de autonomia feminista e de uma estética feminista.

Segundo a autora, a pós-modernidade sucumbe o compromisso com a ação das mulheres, autonomia, crítica social e na configuração de uma utopia feminista. A ideia pós-moderna de que grandes narrativas e projetos civilizatórios não deram o resultado esperado, favorece à falta de perspectiva construtiva de uma nova sociedade e desmobiliza a crítica. Benhabib (2020) defende que não é possível uma crítica sem filosofia robusta, e sem crítica social, um projeto de teoria feminista seria inconcebível. Por essa razão, o comentário feito por Martínez (2003, p. 51) de que o feminismo nada mais é do que uma província de orientação pós-moderna, seria uma completa simplificação.

\subsection{ReVisão das Bases Epistemológicas: Relativismo, ReALismo e OBJetivismo}

A crítica feminista pós-moderna pode ser atrativa por negar tudo que existe na ciência e procurar refúgio em uma outra forma de fazer ciência. Contudo, terá como problema estabelecer relações com o mainstream da ciência, o que acarretará, ao fim e ao cabo, poucas mudanças na institucionalidade científica. Outro questionamento, já sinalizado por Harding, consiste no caráter relativista do argumento utilizado, a saber: tudo que existe como ciência não é legítimo, nem mesmo a verdade, e esse enunciado é verdadeiro.

Em termos de procedimento metodológico para a crítica da ciência, a proposta feminista pós-moderna mostra-se útil. Nesse caso, suspende-se por um momento todos os enunciados de uma dada ciência, para então, reconstruílos identificando os vieses, os preconceitos, as estruturas de poder etc. Esse procedimento crítico pode trazer maior clareza sobre as circunstâncias da produção científica e seus propósitos, mas esta linha ainda terá dificuldades de se desprender do relativismo. Sobre esse assunto, a própria epistemologia feminista tem protagonizado um debate.

Entre as propostas epistemológicas resumidas por Harding, a epistemologia feminista pós-moderna parece ter maiores dificuldades com o 
relativismo. Keller (2005) explica os problemas que uma visão ingênua da ciência acarretariam ao próprio movimento.

O perigo intelectual reside na redução da concepção da ciência a um mero produto social; nesse caso a ciência dissolver-se-ia em ideologia e a objectividade deixaria de ter qualquer sentido intrínseco. Ao resultar no relativismo cultural, qualquer função emancipatória da ciência seria negada e a capacidade de arbítrio da verdade recuaria para campo político. (KELLER, 2005, p. 60)

Aceitar qualquer discurso como equivalente ao científico seria danoso às próprias pretensões feministas que buscam, através de pesquisas sérias, denunciar não apenas os problemas na estrutura da ciência, mas nos próprios resultados de pesquisa. Além disso, facilitaria a aceitação de narrativas pseudocientíficas que rebaixam o papel da mulher na sociedade. Desse modo, o próprio discurso patriarcal, presente na sociedade e especialmente na religião, seria também possível de ser endossado, pois não haveria hierarquia entre conhecimentos científicos e não científicos. Ambos seriam apenas textos ou narrativas que nada tem a ver com uma representação mais ajustada à realidade.

Esses perigos foram bem ilustrados no comentário de Keller (2005):

Em muitos aspectos, o relativismo feminista é um exemplo de passos radicais que transformam o espectro político num círculo. Ao rejeitar a objectividade como um ideal masculino, dá-se voz a um coro inimigo e condenam-se as mulheres a residir fora da 'realpolitik' da cultura moderna; exacerba o problema que se propõe resolver. Anula também o potencial radical da crítica feminista para a compreensão da cultura. (KELLER, 2005, p. 6061)

Um aspecto fundamental no debate epistemológico feminista que não tem sido destacado é justamente esse questionamento ou distanciamento do relativismo. Por mais contraditória que possa parecer à primeira vista, a epistemologia feminista, exceto a linha pós-moderna, não defende o relativismo. Para Harding (2016, p. 25), não se defende que enunciados sexistas e não sexistas sejam equivalentes, ou que a questão da mulher possa ser tratada igualmente em termos biológico ou social. Feministas, e mesmo as pósmodernas, se recusariam a aceitar que o determinismo biológico é uma explicação aceitável, tanto quanto o determinismo social que condicionou ao longo da história o gênero. 
Os enunciados não têm o mesmo peso e valor. A proposta feminista não considera que sua posição mais cética, que aceita o carácter hipotético de muitas afirmações científicas, não implica uma aderência ao relativismo. Como bem observou Keller, essa interpretação aprofunda o problema que pretende resolver e diminui o potencial da crítica feminista sobre a ciência e toda a cultura.

Em outras palavras, o relativismo, nesse caso, traria mais problemas que soluções à argumentação da epistemologia feminista. Um dos problemas é fazer crer que sua visão de mundo é apenas uma das quais dispõe a sociedade, assim como se tem a disposição a visão ideológica dos homens. Assim não seria possível demonstrar nenhuma coerência entre uma narrativa e os fatos que comprovam a exploração da mulher na sociedade.

Com efeito, deve-se rechaçar o relativismo vulgar de todas as formas, tendo em vista que ele garante que se possa falar de tudo e explicar com suposto valor científico qualquer coisa, sem a devida confrontação com os fatos. Quando o discurso feminista alude aos problemas da violência machista na sociedade, 0 faz com dados obtidos em delegacias, entrevistas, questionários, estudos etc., e isso não tem nada de relativo. Esses dados devem ter um peso distinto porque representam melhor traços da realidade da opressão e do agravamento da violência. Assim também não há como adotar um relativismo frente aos resultados de pesquisa sobre o tempo dedicado pelas mulheres aos cuidados com a casa, as crianças e os idosos, comparado ao tempo dispendido pelos homens. Questionar o androcentrismo na ciência, tendo em vista a sua superação e aperfeiçoamento da própria ciência, não pode implicar uma adesão acrítica ao relativismo.

Se a ideia é apresentar os problemas da ciência e das supostas verdades emitidas pelo discurso científico que se entende machistas e androcêntricos, o importante é avançar nas hipóteses que corrijam as representações, rumo a uma nova interpretação mais adequada da realidade.

Nesse sentido, ainda que não se revele no discurso epistemológico feminista pós-moderno, a intenção é fundar uma perspectiva consistente baseada no realismo e, para tanto, deve-se incorporar novos dados que melhor ajudem a compreender os fenômenos. Segundo Susan Babbitt (1992 apud 
SCHERMAN, 2020, p. 40), "a epistemologia feminista é mais bem vista como uma forma especialmente robusta de realismo." Para Scherman (2020, p. 40) não se deve entender que todas as normas epistêmicas são repressivas, ou que todas as contribuições sejam igualmente valiosas para construir o conhecimento, ou que cada um tem a sua realidade e somente ele tem autoridade para falar sobre ela.

Sobre esse relativismo jovial e encantador que está contra todo o estabelecido, que muitas vezes associa-se a linhas políticas do feminismo e a outras posturas pós-modernas, Keller (2005, p. 56) assevera: "Penso que é mesmo possível usar o pensamento feminista para iluminar e clarificar a substrutura da ciência (que pode historicamente ter ficado distorcida) para preservar o que a ciência nos ensinou, nomeadamente sermos mais objectivos."

É importante restaurar a importância da ciência, e nesse ponto, a crítica feminista à epistemologia pode ser muito bem-aceita para evitar, além do relativismo, formas de anticientificismo presentes na sociedade. Tal como comentado por Scherman (2020, p. 39),

[...] há muito tempo as feministas têm também observado que as variedades de relativismo são profundamente problemáticas por razões políticas, além dos escrúpulos epistemológicos ou lógicos que possamos compartilhar com os colegas nãofeministas.

Contudo, o feminismo de viés relativista e também anticiência está presente no debate, como bem reconhece Rose:

\begin{abstract}
Esse trabalho crítico, se bem que por vezes seja um aliado desconfortável, não é equacionável com feminismo anticiência uma corrente de que discordo mas que, sem dúvida alguma, existe no interior do feminismo contemporâneo. Ao invés, a crítica feminista da ciência tende a ser particularmente respeitadora do trabalho das feministas nas ciências e da sua tarefa, paciente e tecnicamente existente, de construção de novas representações da natureza em consonância com os valores feministas. (ROSE, 2005, p. 115).
\end{abstract}

Como visto, deve-se reconhecer e valorizar o trabalho árduo de várias feministas que também são mulheres cientistas que estão promovendo pesquisas em várias áreas para o próprio bem-estar da população. Como seria possível abrir mão dos avanços na medicina promovidos pela perspectiva de gênero? Entende-se ainda que Rose aponta outras propostas para a ciência, 
como a importância de instaurar novos valores, mais feministas, no interior da ciência para o bem-estar de toda a população.

Nesse sentido, o desprestígio da ciência ou transformá-la em um gueto dominado por homens competitivos e com uma relação predatória da natureza não seria uma estratégia benéfica. Esse sujeito do conhecimento deve ser investigado e as limitações que produz no desenvolvimento humano devem ser compreendidas. Sherman comenta que

Não surpreendentemente, grande parte do trabalho das epistemólogas feministas tem sido argumentar que o sujeito filosófico alegadamente genérico tem sido, para a maioria dos filósofos modernos, normativamente masculino, branco, cristão, fisicamente capaz, não fazendo parte da classe trabalhadora e heterossexual. (SCHERMAN, 2020, p. 33).

Destaca-se ainda outro aspecto importante para reinaugurar um novo objetivismo e uma nova relação com a natureza, de acordo com a crítica epistemológica de Rose (2005). Trata-se de, dentro do marco de uma nova objetividade, superar a noção de dominação presente na ciência. Essa pulsão desenfreada pela conquista atribuída ao universo masculino foi identificado pelas análises feministas.

Contra isto, quero insistir em que os estudos feministas da ciência e da tecnologia são diferentes no facto de, se bem que incluam quase todas as abordagens metodológicas e disciplinares concebíveis, terem um profundo compromisso com a possibilidade de produzir melhores e mais fidedignas representações da natureza a partir de valores novos. (ROSE, 2005, p. 110).

Esses novos valores não querem dizer um abandono aos ideais representados pela ciência. Embora a instituição científica atual não represente esses valores integralmente, recusar-se à busca de alguma objetividade e atenção aos fatos pode trazer sérios problemas.

Outra questão associada à crítica ao relativismo, é a forte presença da noção de dominação da natureza, justificada de várias formas. Segundo pontua Rose (2005, p. 113), a tradição judaico-cristã e a ciência ocidental têm a natureza e as mulheres como objetos de dominação, embora atualmente haja uma tentativa de esconder esses propósitos, tendo em vista a vigília dos movimentos feministas e do ambientalismo. "Contudo, o alargamento da dominação tal como 
ela se exprime diariamente no laboratório existe na linguagem e nas práticas que, crescentemente, tratam os animais como se fossem permutáveis com reagentes químicos." (ROSE, 2005, p. 115)

O que ensina as epistemologias feministas é a reconciliação com a natureza e com os valores mais honestos em relação aos demais seres no que tange a busca de conhecimentos científicos. Esse novo objetivismo deve ser mais comprometido com os valores éticos e humanitários. Para Keller (2005, p. 62) "Ao alargar a crítica dos fundamentos do pensamento científico, o primeiro passo será, por isso, reconceptualizar a objectividade como um processo dialéctico a fim de permitir a possibilidade de distinguir o esforço objectivo da ilusão objectivista."

Nesse sentido, o afastamento de uma ilusão simplista de objetividade para projetar uma nova objetividade compromissada e dialética, não significa a recusa ao científico e ao esforço de objetividade. O que é problemático na ciência não é a busca de mais rigor, mas a relação entre rigor, suposta objetividade e uso do conhecimento científico para explorar e dominar o outro. Como bem pontuou Keller (2005, p. 62) "Os ingredientes ideológicos que preocupam particularmente as feministas encontram-se onde a objectividade se liga à autonomia e à masculinidade e onde, por sua vez, os objetivos da ciência se articulam com poder e a dominação." Acredita-se que esse é o ponto central da crítica à ciência das epistemologias feministas.

Nesse sentido, a atividade científica não seria o problema, mas a prática científica que fomenta as relações de poder, dominação e ideologia abstrata de uma fácil objetividade. No campo da primatologia, por exemplo, Haraway (2005, p. 103) argumenta que "Podemos conhecer os nossos corpos, outros animais, fósseis, etc. enquanto objectos de investigação científica e, simultaneamente, reconhecer que a nossa intervenção na construção do objecto é historicamente condicionada." Em outras palavras, o conhecimento metódico e a prática contínua de buscar a melhor representação do objeto, condicionada socialmente, não deve desmobilizar a intenção de explicação.

Como visto, as três respostas epistemológicas, a empirista, a da perspectiva feminista e a feminista pós-moderna, são formas para refletir a 
inserção das teorias feministas na ciência, das ciências mais duras às nitidamente "moles", flexíveis e mais abertas. A crítica ao relativismo e a reconstituição de uma nova objetividade são elementos importantes do debate epistemológico feminista.

Entre as críticas, a de natureza radical na proposta de Keller (2005), é a que poderia receber maior interesse das demais ciências. Dentro da proposta radical, não basta alcançar posições de poder dentro da ciência como se naturalmente isso fosse corrigir as inclinações androcêntricas e os vieses presentes em ciências duras e "moles".

No caso da medicina o fenômeno é marcante, pois diversas intervenções foram desenvolvidas sob um universo masculino sem respeitar características das mulheres que somente agora têm sido levantado pelo crescente número de pesquisadoras no campo da saúde. Um exemplo, nesse sentido, é a ênfase da indústria farmacêutica na realização de experimentos com maioria de sujeitos homens. Essas práticas produziram o que se tem discutido atualmente com a expressão "lacuna de dados" (brecha de datos ou data gap).

Atualmente, encontra-se em um estágio de desenvolvimento científico em que é necessário reconhecer que vários resultados de pesquisa (medicina e engenharia, por exemplo) não levaram em conta dados suficientes do universo feminino, bem como os efeitos que medicamentos, procedimentos, obras, equipamentos etc., impõem ao coletivo de mulheres. Isso pode ser claramente entendido como a inclinação androcêntrica das pesquisas. Keller (2005, p. 59) lembra que "Mais difícil é lidar com uma crítica verdadeiramente radical que procura localizar as distorções mesmo nas ciências 'duras' e na ideologia científica." Essas críticas radicais condenam a simplificação da objetividade e da racionalidade, bem como a sua instrumentalização.

Essa revisão da objetividade encontra guarida na proposta de Scheman (2020) que questionou algumas concepções da epistemologia tradicional: entende que o conhecimento não se dá de maneira individualista como pregam; a necessidade de atenção à diversidade; e a noção de objetividade como meta do conhecimento e como o conhecimento é definido na prática em contraste com opinião. Assim, assemelha-se a questões epistemológicas discutidas 
anteriormente, não obstante, considera-se apropriada a contestação da definição de conhecimento como crença verdadeira justificada.

Retomando o problema de Gettier (2013), Scheman (2020) ilustra que alguém pode estar inclinado a justificar a crença de que uma proposição "p" poderia ser verdadeira. Mesmo assim, não se teria segurança para afirmar que alguém conhece uma proposição "p", porque a relação entre uma proposição "p" para ser verdadeira e a crença em uma proposição "p", segundo argumenta, é fortuita. Utilizando um contraexemplo sustenta que

[...] nenhuma abordagem da justificação pode preencher completamente a lacuna entre o mundo e nossas crenças sobre ele - nenhuma metodologia é infalível; o sonho cartesiano de um procedimento interno de verificação suficientemente forte para afastar a possibilidade de erro é irrealizável. (SCHERMAN, 2020, p. 42).

Em outras palavras, entre o mundo e as crenças há uma lacuna que, de acordo com a autora (2020, p. 43), é social e político e relaciona-se com confiança, dependência, valores, interesses, solidariedade, negociação com o poder e privilégio. Essa questão da epistemologia feminista parece fundamental. Isto é, saber como se adquire uma crença e quais modos de aquisição e validação para que elas se tornem confiáveis passem para estágio de conhecimento. Essas questões relacionam-se com o pragmatismo clássico. Isso mostra que se deve preocupar-se com as lacunas no reino da descoberta. Contudo, sustenta-se que uma epistemologia feminista pode muito bem questionar o processo de descoberta e pensar nos limites da justificação, mas não o abandono completo da justificação.

Para encerrar, é necessário reinserir na epistemologia a importância da emoção, tal como presente na epistemologia de Charles Peirce (1980) que destaca as categorias do conhecimento e como o sentimento faz parte de uma teoria do conhecimento. Scheman (2020), desde a perspectiva da epistemologia feminista, e Peirce (1980) desde o pragmatismo, entendem a emoção e a sensação dentro do processo racional.

Segundo Scheman (2020), as emoções foram abordadas como não confiáveis epistemologicamente por terem a sua validade apenas junto as pessoas que manifestaram as mesmas emoções. Por outro lado, as emoções 
representam formas femininas de conhecer, as quais deveriam ser evitadas por completo. Essa desconfiança das emoções tira a oportunidade de tratá-las em termos heurísticos como contributos para a descoberta de novas hipóteses. Assim como as emoções, outras maneiras de conhecer foram rechaçadas, contudo, de acordo com Scheman (2020), inserida na vertente do ponto de vista feminista, a experiência dos privilegiados por proporcionar a identificação de lacunas, o que em si oferece uma visão mais literal das contradições, isto é, uma leitura mais completa das consequências dos fenômenos estudados.

\section{CONCLUSÕES}

Nesta breve análise identificou-se a dificuldade de pensar o feminismo como uma corrente coesa. Essa dificuldade está refletida também nas epistemologias feministas que são respostas aos problemas centrais que se impõem ao feminismo na ciência.

As perspectivas empirismo feminista, ponto de vista feminista e pósmodernismo feminista, são formas de responder a tais problemas. Contudo, cada um possui limitações, mas são fundamentais para a reflexão da relação entre feminismo e ciência.

Além disso, a grande contribuição das epistemologias feministas está na crítica radical da ciência porque provoca uma discussão já inaugurada pelos pósmodernos, mas que não coincide com alguns de seus resultados. Para as epistemologias feministas, assim como para o próprio movimento feminista, é necessário um combate ao relativismo, uma reinstauração do realismo e de um objetivismo mais potente que seja aperfeiçoado pela visão das mulheres, além, é claro, da redução do paradigma do domínio da natureza e da sociedade e a inclusão de outros tipos de conhecimento como importantes para o início do processo heurístico, tal como a emoção (presente nas primeiras abduções).

Com base nos argumentos relacionados anteriormente, pode-se refletir sobre a ciência da informação e como as pesquisas no campo têm se posicionado frente às premissas epistemológicas feministas lançadas aqui. Em discussão posterior, poder-se-á constatar como a ciência da informação tem incorporado discussões identificadas às epistemologias feministas. 


\section{AGRADECIMENTO}

O presente trabalho foi realizado com apoio da Coordenação de Aperfeiçoamento de Pessoal de Nível Superior - Brasil (CAPES) - Código de Financiamento 001 (Processo: 88887.571329/2020-00).

\section{REFERÊNCIAS}

BENHABIB, Seyla. Feminismo y posmodernidad: una difícil alianza. In: AMOROS, C.; MIGUEL, A. de. (ed.). Teoría feminista: de la llustración a la globalización 2, del feminismo liberal a la posmodernidad. Madrid: Biblioteca Nueva, 2020. Cap. 10, p. 319-342.

BORGES, lara Farias. Bancada feminina no Senado terá 12 integrantes em 2019. Senado Notícias, 31/01/2019. Disponível em: https://www12.senado.leg.br/noticias/materias/2019/01/31/bancada-femininano-senado-diminui-em-2019. Acesso em: 29/06/2021.

GETTIER, Edmund L. Conhecimento é crença verdadeira justificada? Perspectiva Filosófica, Recife, v. 1, n. 39, p.124-127, jan./jun. 2013.

HARAWAY, Donna. Manifiesto cíborg: ciencia, tecnología y feminismo socialista a fines del siglo XX. 2. ed. Antequera, Málaga: Kaótica Libros, 2020.

HARAWAY, Donna. Sociologia animal e economia natural do corpo político, parte II: o passado é um campo de batalha. In: LEVY, Teresa; QUEIROZ, Clara. (org.). Ciência e género: quatro textos de quatro mulheres. Lisboa: Cadernos de Filosofia das Ciências - CFCUL, 2005. p. 79-108.

HARDING, Sandra. Ciencia y feminismo. San Sebatián de los Reyes: Ediciones Morata, 2016.

KELLER, Evelym Fox. Feminismo e ciência. In: LEVY, Teresa; QUEIROZ, Clara. (org.). Ciência e género: quatro textos de quatro mulheres. Lisboa: Cadernos de Filosofia das Ciências - CFCUL, 2005. p. 55-79.

MARTÍNEZ, Miguel. Epistemología feminista y postmodernidad. Cinta Moebio: Revista de Epistemología de Ciencias Sociales, San Tiago, v. 16, p. 50-56. 2003. Disponível em: www.moebio.uchile.cl/16/martinez.html. Acesso em: 12 dez. 2021.

PEIRCE, Charles Sanders. Escritos coligidos. 2. ed. São Paulo: Abril Cultural, 1980.

PÉREZ PRIETO, Laura. Epistemología feminista y conocimientos desde el Sur global. Ecología Política: Cuadernos de Debate Internacional, Vilanova i la 
Geltrú (España), v. 54, p. 65-69, 2017.

RODRÍGUEZ MAGDA, Rosa María. Género. In: COBO BEDIA, R.; RANEA TRIVIÑO, B. (ed.). Breve diccionario de feminismo. Madrid: Editorial Catarata, 2020. p. 119-121.

ROSE, Hilary. Epílogo: o trabalho das mulheres nunca está feito. In: LEVY, Teresa; QUEIROZ, Clara. (org.). Ciência e género: quatro textos de quatro mulheres. Lisboa: Cadernos de Filosofia das Ciências - CFCUL, 2005. p. 109 130.

SANTOS, B. S. Introdução a uma ciência pós-moderna. 3. ed. Rio de Janeiro: Graal, 2000.

SAU, Victoria. Diccionario ideológico feminista I. Barcelona: Icaria, 2000.

SCHEMAN, Naomi. Epistemologia feminista. Revista Ideação, Feira de Santana, n. 42, p. 30-44, jul./dez. 2020.

SCHIEBINGER, Londa. Has feminism changed science? Cambridge: Harvard University Press, 2001.

SERRET BRAVO, Estela. Epistemología feminista. In: COBO BEDIA, R.; RANEA TRIVIÑO, B. (ed.). Breve diccionario de feminismo. Madrid: Editorial Catarata, 2020. p. 85-87.

VARELA MENÉNDEZ, Nuria. Feminismo para principiantes. Barcelona: Penguin Random House Grupo Editorial, 2019.

\title{
FEMINIST EPISTEMOLOGIES AND INFORMATION SCIENCE: INTRODUCTORY NOTES
}

\begin{abstract}
Objective: Considering the answers to the central problems referring to feminism in science, this paper aims to show the general topics of discussions in feminist epistemologies to support of the article that will deal with their developments in information science. Methodology: The study used a bibliographic approach, but was written like an essay. In Part I, the difficulty of thinking feminism as a cohesive current was identified. Therefore, it was necessary to review the basic concepts of the discussion. Results: The feminist empiricism, feminist point of view, and feminist postmodernism perspectives are ways to respond to the epistemological problems of science. However, they have got limitations, although they are fundamental to think about the relationship between feminism and science. Conclusions: Feminist epistemologies, as well as for the feminist movement itself, have to fight against relativism, a reinstatement of realism and more powerful objectivism that is perfected by the vision of women is necessary, in addition to reducing the paradigm of the domain of nature and society, and the inclusion of other types of knowledge as important for the beginning of the heuristic process, such as emotion. Based on the related arguments, Part II of this article can be reflected on information science and how research in the field
\end{abstract}


has positioned itself against feminist epistemological premises.

Descriptors: Feminist Epistemologies. Information Science. Feminist Empiricism. Feminist Point of View. Objectivism.

\title{
EPISTEMOLOGÍA FEMINISTA Y CIENCIA DE LA INFORMACIÓN: NOTAS INTRODUCTORIAS
}

\begin{abstract}
RESUMEN
Objetivo: Considerando las respuestas a los problemas centrales que se enfrenta el feminismo en la ciencia, el artículo presenta los temas generales presentes en las epistemologías feministas, con lo cual apoyará el artículo, cuyo reto será abordar los desarrollos de esta teoría em la ciencia de la información. Metodología: El estudio utilizó un enfoque bibliográfico, pero se redactó en forma de ensayo. En la primera parte se identificó la dificultad de pensarse en el feminismo como una corriente cohesionada. Por tanto, fue necesario revisar los conceptos básicos de la discusión. Resultados: El empirismo feminista, el punto de vista feminista y las perspectivas del posmodernismo feminista son formas de responder a los problemas epistemológicos de la ciencia. Sin embargo, poseen limitaciones, aunque sean fundamentales para relfexionar sobre la relación entre feminismo y ciencia. Conclusiones: Para las epistemologías feministas, así como para el propio movimiento feminista, es necesaria una lucha contra el relativismo, una reinstalación del realismo y un objetivismo más potente que se perfeccione con la visión de la mujer, además de reducir el paradigma del dominio de la naturaleza y de la sociedad. Se debe incluir otros tipos de conocimientos importantes para el inicio del proceso heurístico, como la emoción. Con base en los argumentos relacionados se podrá reflexionar sobre la ciencia de la información y cómo han sido sus investigaciones frente a las premisas epistemológicas feministas.
\end{abstract}

Descriptores: Epistemologías feministas. Ciencia de la Información. Empirismo feminista. Punto de vista feminista. Objetivismo.

Recebido em: 31.08 .2021

Aceito em: 31.08 .2021 